\title{
LEISHMANIASIS EN COYO ORIENTE. MigRantes TRASANDINOS EN SAN PEDRO DE ATACAMA
}

\author{
María Antonietta Costa ${ }^{1}$ y Agustín Llagostera ${ }^{2}$
}

\section{* Introducción}

Resumen

En el cementerio arqueológico de Coyo Oriente se detectaron cráneos femeninos con extensas lesiones destructivas, especialmente en la órbita y nariz. Pequeñas porciones de material óseo de los bordes de las lesiones fueron sometidas a análisis molecular por amplificación del ADN de leishmaniasis, lo que hizo posible diagnosticar positivamente esta enfermedad. Se analiza la patología de estos cráneos y los elementos biológicos y culturales asociados con ellos, así como el contexto bioantropológico y cultural en que estos individuos se encontraban insertos. Dado que el vector de esta enfermedad nunca estuvo presente en el ambiente árido de San Pedro de Atacama, se postula que estas personas serían originarias de alguna zona trasandina, habiendo llegado a la localidad en calidad de migrantes, con el patógeno latente. El hecho de que todos los cráneos correspondan a individuos del sexo femenino sugeriría la posibilidad de que su presencia en San Pedro de Atacama obedeciera a un sistema patrilocal de alianzas matrimoniales.

Palabras claves: leishmaniasis - arqueología - paleopatología San Pedro de Atacama.

Abstract

Female skulls with massive destructive lesions, especially in orbit and nose were found in San Pedro de Atacama in the archaeological Coyo Oriente cemetery. Bone fragments from the edges of the lesions were subjected to molecular analysis by PCR DNA amplification which enabled us to diagnose leishmaniasis disease. This article examines the pathology of these skulls and biological and cultural elements associated with them, as well, the cultural and bioantropological context in which these individuals were inserted. Since the vector of this disease was never present in the arid environment of San Pedro de Atacama, it is postulated that these people would be originating on the other side of the Andes, where this disease is endemic. They can arrived to the area with some latent stage of the disease. The fact that all of them are women, suggests that their presence in San Pedro de Atacama could obey to a patrilocal system of marriage alliances.

Key words: leishmaniasis - archaeology - paleopathology San Pedro de Atacama.
El cementerio arqueológico de Coyo Oriente se ubica en el ayllu de Coyo en San Pedro de Atacama, norte de Chile (Figura 1). Fue excavado por Le Paige (1972-73) y sus contextos, ubicados cronológicamente entre $500 \mathrm{y}$ 1000 DC, han sido ampliamente citados en la literatura arqueológica. De hecho, sirvieron como base a Tarragó (1989) para definir la segunda fase del período Medio en el salar de Atacama, denominada "Coyo", de acuerdo al criterio de sitio-tipo, y que forma parte de la secuencia propuesta para la etapa agroalfarera local. Es durante esos momentos cuando en los oasis de Atacama se dejan sentir fuertes influencias de Tiwanaku, observadas principalmente en la iconografía desplegada en diversos tipos de objetos; igualmente se registran evidencias de vínculos con otras zonas, como el sur de Bolivia y el Noroeste Argentino.

Le Paige (1972-73) señala que las excavaciones en este sitio proporcionaron 115 cuerpos en la parte norte (dentro de un potrero) y 178 en la zona sur (fuera del potrero), dando un total de 293 cuerpos procedentes de 160 tumbas. En sus apuntes de terreno, señala claramente las tumbas pertenecientes a la Zona Norte así como a la Zona Sur del cementerio; sin embargo, luego describe otro conjunto de tumbas de la "parte sur del cementerio", sin especificar a cuál de las dos zonas del sitio se refiere. A juzgar por los contextos, este grupo de tumbas (que hemos denominado Zona Sur-Sur) con 106 cuerpos, tiene más proximidad ergológica con la Zona

Recibido: julio 2013. Aceptado: enero 2014.

\footnotetext{
1 Instituto de Investigaciones Arqueológicas y Museo R. P. Gustavo Le Paige, Universidad Católica del Norte. Calle Gustavo Le Paige 380, San Pedro de Atacama, CP. 1410000, CHILE. Email: ma.costa@vtr.net

2 Instituto de Investigaciones Antropológicas, Universidad de Antofagasta. Avenida Angamos 6o1, Antofagasta, CHILE. allagostera@vtr.net
} 


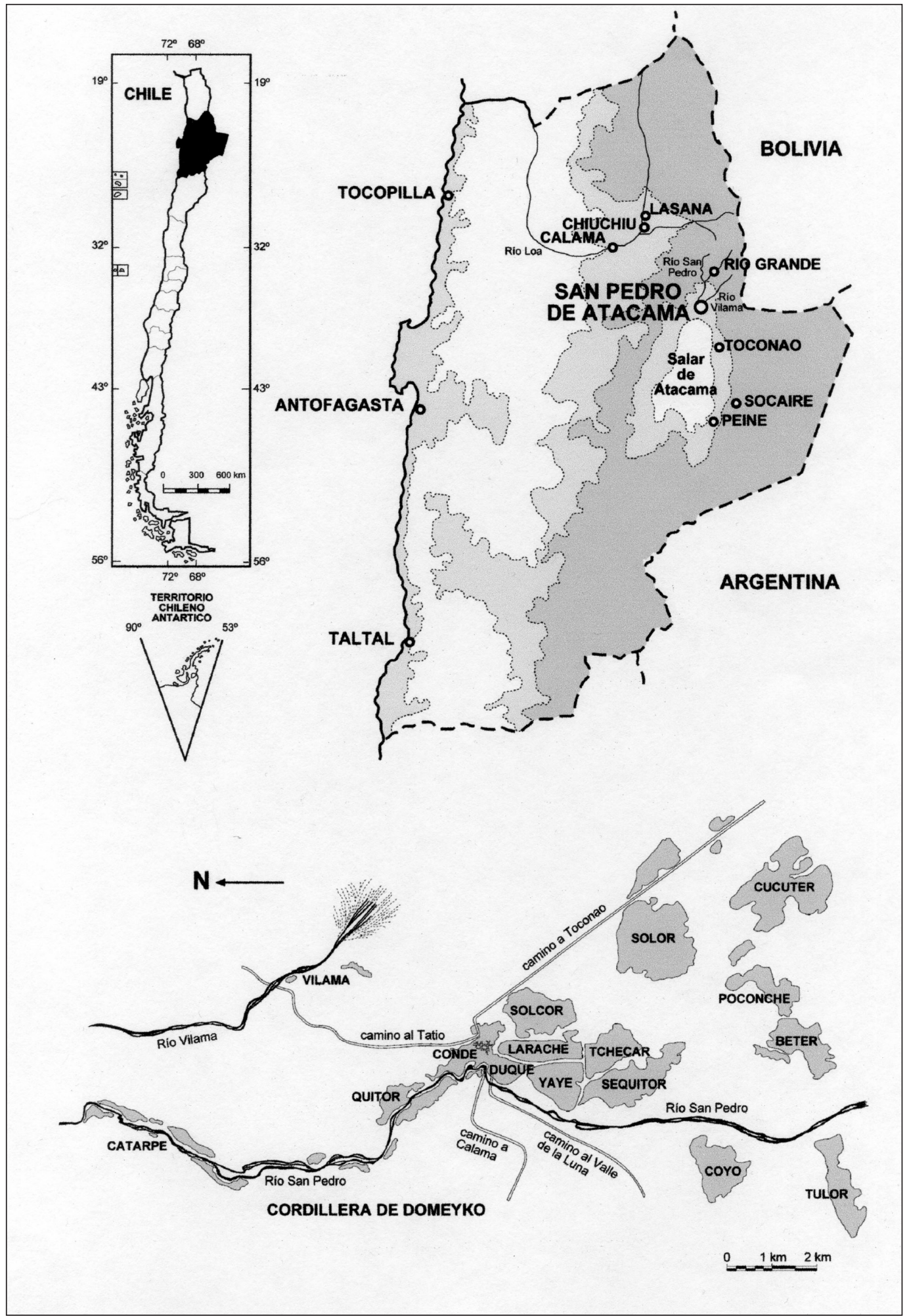

Figura 1. Mapa con la ubicación de San Pedro de Atacama y de la localidad de Coyo donde se ubica el cementerio arqueológico Coyo Oriente. 
Sur. Considerando las tres zonas de Coyo Oriente, el total de cuerpos excavados llega a 399.

En los contextos, además de la alfarería, cestería, tejidos, gorros, tabletas para inhalar alucinógenos y numerosos cestos bordados con lanas de colores (tipas) que se han asociado con el Noroeste Argentino (Llagostera 1995), se encontró lo que Le Paige denominó "martillos-maza" de piedra, relacionados con actividades mineras, y que hasta el momento no han sido hallados en otros yacimientos. A esto se suma el hecho de que este sitio posee el más alto número de tabletas tiwanaku traídas desde el exterior (Llagostera 2006a).

Para Coyo Oriente se cuenta con varios fechados radiocarbónicos aportados por Oakland (1992), pero sin especificar sectores, los que van de 639 a 910 DC, a los que se suman cinco fechados por termoluminiscencia publicados por Costa y colaboradores (2008) cuyo objetivo fue obtener hitos cronológicos para cada una de las tres zonas referidas.

\section{* Descripción del material}

En el cementerio arqueológico de Coyo Oriente se detectaron cinco ${ }^{3}$ cráneos con extensas lesiones destructivas en uno de los lados de la cara, especialmente en órbita y nariz, con abundante formación de tejido perióstico, el que se presenta como una extensa porosidad gruesa y profunda, existiendo aún la formación de cloacas de supuración. Se trata de individuos femeninos de entre 30 y 49 años, con una fuerte pérdida de piezas dentales en vida, a lo que se suma la pérdida post-mortem de las piezas anteriores. Uno de ellos presenta deformación tabular erecta, otro tiene la variedad circular oblicua y los dos restantes no están deformados. Tres de los enterratorios fueron exhumados en la Zona Sur del cementerio (3938, $3984,4156)$, en tanto que del cuarto (5377) no se especifica su asignación. Uno de estos enterratorios contenía solo al individuo afectado (4156); otro albergaba un hombre, la mujer afectada y dos fetos (3938); un tercero correspondía a tres adultos y un niño pequeño (5377), y en el último, fueron enterradas tres mujeres (3984).

\footnotetext{
3 Muestras de los cinco ejemplares fueron enviadas para análisis de $\mathrm{ADN}$, el que fue posible realizar solamente en cuatro de ellos, y son a los que nos referiremos en este trabajo.
}

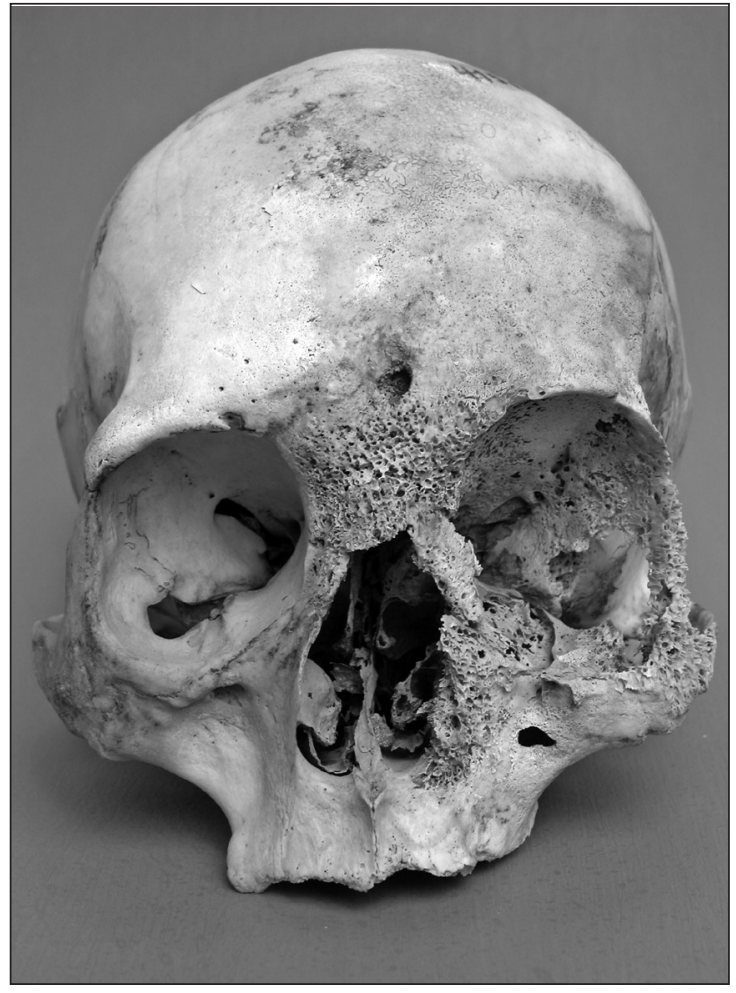

Figura 2. Cráneo 4156 ( $\mathrm{N}^{\circ}$ Catálogo 12204).

Cráneo 4156 ( $N^{\circ}$ Catálogo 12204). Individuo femenino, de 4549 años de edad, sin deformación craneana. Enterratorio individual de la Zona Sur. El contexto está compuesto por un ejemplar de alfarería negra grabada y un fragmento de urna, un cesto, dos bolsitas (una con quinoa y otra con lana y pelo humano). Posee una extensa lesión que compromete el lado izquierdo de la cara, especialmente la órbita hasta el borde de la apertura periforme de la nariz, hueso nasal, vómer, cornetes, malar, etmoides, esfenoides, apófisis ascendente y apófisis piramidal de la maxila y el frontal. El reborde orbitario inferior se aprecia muy destruido y la porción del frontal y el de la maxila izquierda, muy adelgazados. En la glabela y en la porción media de la maxila, hay dos cloacas de supuración. La lesión empezaba a extenderse también hacia el lado derecho de la cara, en el hueso nasal y en el frontal, en la región de la glabela y también hacia la porción media del frontal, en forma de periostitis; el mayor compromiso se encuentra alrededor de la cloaca en la glabela. Las alteraciones en el material óseo se presentan como una extensa porosidad gruesa y profunda. El paladar no está afectado. Mandíbula ausente (Figura 2). 


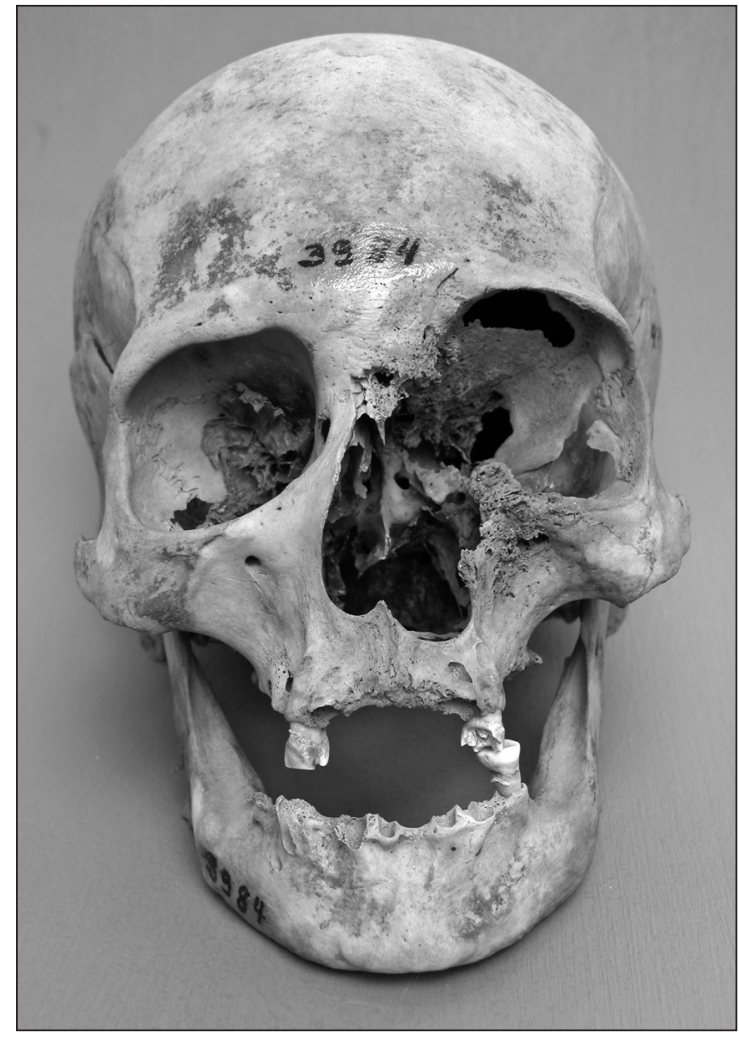

Figura 3. Cráneo 3984 (N Catálogo 9791).

Cráneo 3984 ( $N^{\circ}$ Catálogo 9791). Individuo femenino, de 30-34 años de edad, sin deformación craneana, procedente de un entierro múltiple de tres adultos en la Zona Sur. El contexto es indiferenciado en cuanto a su atribución a alguno de los ocupantes de la tumba, y está compuesto por una vasija cerámica común, un cesto y una calabaza. La lesión se encuentra en el lado izquierdo de la cara, comprometiendo las regiones orbicular y nasal, afectando los huesos nasales, apófisis ascendente y piramidal de maxila, etmoides, porción orbital del frontal, porción posterior del palatino; están destruidos el vómer y ambos cornetes. Se verifica el adelgazamiento del contorno del borde orbitario en toda su extensión. Se observa la ausencia de casi todo el techo de la órbita. La celda etmoidal izquierda se encuentra muy ensanchada, formando una cloaca de supuración; otra cloaca más pequeña se observa en el borde nasal del hueso frontal. Entre glabela, escotadura nasal y borde orbitario se verifica un rasgo similar a una fractura vertical, con depresión del hueso hacia el lado izquierdo. La mandíbula no está afectada (Figura 3).

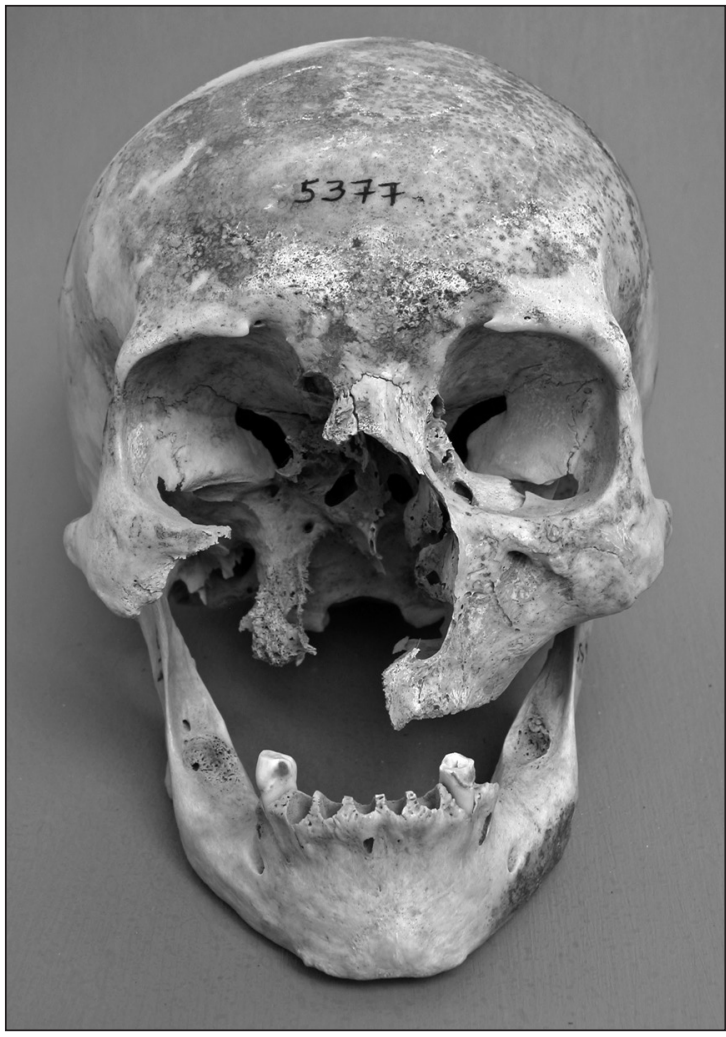

Figura 4. Cráneo 5377 ( $N^{\circ}$ Catálogo 9858).

Cráneo 5377 ( $N^{\circ}$ Catálogo 9858). Individuo femenino de 3539 años, con deformación craneana circular oblicua. Proviene de un entierro múltiple compuesto por tres adultos y un bebé. No se sabe la zona de procedencia. El contexto es indiferenciado y se compone de 20 vasijas cerámicas (una grabada), un capacho, cuatro cestos (uno bordado o tipa), una cuchara, tres calabazas, dos conchas de caracol (Strophocheilus oblongus), un collar de malaquita y una bolsita con tierra roja. Presenta lesiones en el lado derecho de la cara. Están ausentes el maxilar y los huesos de la nariz. La apófisis piramidal derecha está completamente deformada por porosidades. La parte posterior de la región de la nariz se encuentra igualmente remodelada. El cigomático está incompleto y remodelado por procesos de absorción del hueso. El lado izquierdo del paladar está parcialmente destruido, así como los cornetes de ese mismo lado, presentando porosidades en los bordes, por lo que se podría pensar que por lo menos gran parte de los huesos faltantes habrían sido destruidos por la patología. Hay adelgazamiento del reborde orbital en sus porciones 
del malar y del frontal. La mandíbula no presenta alteraciones (Figura 4).

Cráneo 3938 ( $N^{\circ}$ Catálogo 14673). Individuo femenino de entre 40-44 años con deformación craneana tabular erecta. Proviene de un entierro múltiple de un hombre, una mujer y dos fetos, de la Zona Sur. El contexto es femenino, compuesto por cuatro vasijas cerámicas, un cesto y un collar de malaquita. El lado derecho de la cara está destruido por la lesión. La mandíbula no está afectada por lesiones (Figura 5).

La determinación del sexo y de la edad se basaron en las características sexualmente dimórficas del cráneo y por el grado de las suturas craneanas, respectivamente (Buikstra y Ubelaker 1994).

\section{* Análisis molecular}

Dado que lesiones similares son también producidas por cáncer, lepra, trepanosomiasis, tuberculosis y otras infecciones crónicas (Ortner y Putschar 1981), fue necesario recurrir a técnicas de laboratorio específicas para determinar la etiología de la enfermedad y contrastar la hipótesis previa de que se trataría de leishmaniasis; los análisis moleculares fueron realizados en el Paleo-DNA Laboratory de Lake Head University, Ontario (Costa et al. 2009).

Se diseñó un método mejorado de detección para el ADN de leishmaniasis con la sensibilidad aumentada y especificidad para el parásito. Para ello, se recurrió al análisis de las secuencias nucleotídicas obtenidas de muestras de ADN, a partir de raspaduras en los márgenes de las lesiones de los huesos afectados de los individuos, las que fueron aisladas y amplificadas por PCR (reacción en cadena de la polimerasa). Con la aplicación de este método molecular se logró la identificación del organismo causante en tres de las muestras. El cuarto (3938) fue asignado al mismo agente causal por inferencia. Los resultados se contrastaron con los datos de ADN de leishmaniasis disponibles en las bases de datos, información proveniente de dos especies: Leishmania major y Leishmania donovani.

Se comenzó amplificando el ADN extraído de las secciones de tejidos de las muestras 1 a 3 (4156, 3984 y 5377),

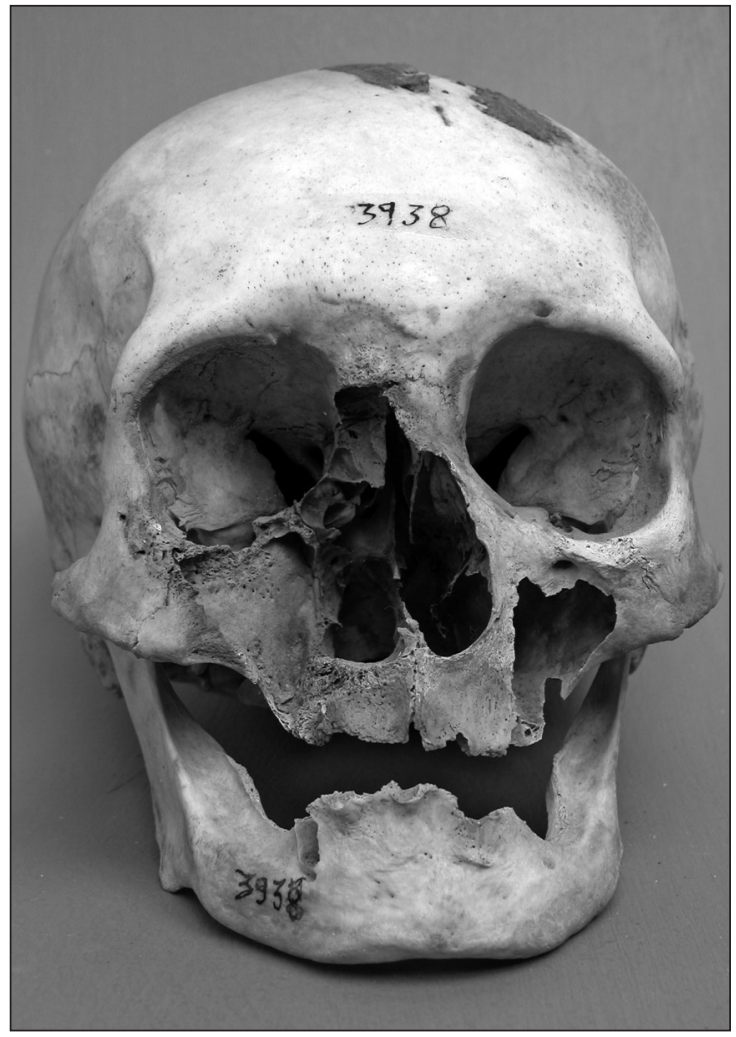

Figura 5. Cráneo 3938 ( $\mathrm{N}^{\circ}$ Catálogo 14673).

con cuatro conjuntos de partidores específicos para cada uno de los genes a investigar. El análisis arrojó una banda de 118 pares de bases para el gen IMP deshidrogenasa en la muestra 2 y una banda de 184 pares de bases de un fragmento del mini círculo del cinetoplasto en las muestras 1 y 2, lo cual indicó el éxito de la amplificación.

A continuación se examinaron todos los conjuntos de partidores en la totalidad de las muestras óseas. Las amplificaciones dieron como resultado un fragmento de 118 pares de bases para el gen IMP deshidrogenasa, un fragmento de 131 pares de bases para el gen codificante para el aminoácido permease AAP13LD de la muestra 3 y un fragmento de 220 pares de bases para el gen adenilato quinasa de la muestra 1.

Cuatro genes del genoma de Leishmania fueron elegidos dentro de un conjunto de cuatro pares de oligonucleótidos diseñados a partir de una búsqueda bibliográfica, y la estabilidad y la función de los genes dentro del genoma 
de Leishmania donovani. El diseño inicial tuvo como fin encontrar una secuencia adecuada de 18 bases de longitud acoplada a una segunda secuencia para producir un tamaño del amplicón (fragmento de ADN producido en la PCR) de no más de 300 pares de bases. Se realizó una búsqueda nucleótido-nucleótido BLAST (blastn) estándar, para comprobar el origen específico de la secuencia en cuestión, seguido de la determinación de la temperatura de alineamiento mediante la herramienta "Oligos Toolkint" de QIAGEN.

Se continuó el análisis del amplicón utilizando un programa informático de PCR simulado para determinar la especificidad y la estabilidad del partidor y para visualizar la sensibilidad de cada amplicón. La secuencia que se generó no coincide exactamente con la de Leishmania donovani, por lo cual no se ha logrado determinar la especie correcta. Sin embargo, la clonación y secuencia de estos productos confirmaron definitivamente la presencia de ADN de leishmaniasis en las muestras. Independientemente de cualquier especie de que se trate, el resultado es suficiente para confirmar la presencia de la infección tropical en el material analizado (Costa et al. 2009).

\section{* Distribución de la leishmaniasis}

La leishmaniasis es una enfermedad polimórfica causada por más de 30 especies de protozoarios del género Leishmania (World Health Organization [WHO] 2007), con reservorios en diferentes mamíferos, y transmitida a través de la picadura de la hembra de varias especies de mosquitos del género Phlebotomus, en el Viejo Mundo y de Lutzomyia en las Américas. Estos mosquitos vectores de los protozoarios se caracterizan por necesitar ambientes calurosos, de alta humedad y con mucha vegetación, siendo endémicos de las regiones que presentan esas condiciones.

Son reconocidas tres formas clínicas principales de leishmaniasis (WHO 2007): "visceral" causada por Lutzomyia donovani, "cutánea" (leishmaniasis andina, "uta" o "úlcera del chiclero") causada por Lutzomyia mayor y "mucocutánea", también conocida como selvática o "espundia". Esta última es causada por cerca de 20 especies de flebótomos, entre ellos, Lutzomyia braziliensis, Lutzomyia peruviana y Lutzomyia mexicana. La leishmaniasis mucocutánea es considerada autóctona en América del Sur. Marzochi y Marzochi (1994) plantean que la enorme cantidad y densidad de especies de flebotomíneos en la Amazonía, aunada a la mayor homogeneidad genética intrarregional del parásito, estaría indicando la región de los tributarios del margen derecho al sur del río Amazonas como el lugar de origen del complejo de Lutzomyia braziliensis, vector de la leishmaniasis mucocutánea.

La leishmaniasis mucocutánea, tema de este trabajo, se origina a partir de la picadura de la hembra de una de las especies de flebótomos mencionadas, lo que produce una o varias lesiones en la piel, la que puede curarse espontáneamente. No obstante, a partir de la lesión inicial cicatrizada, los parásitos se diseminan por vía linfática y sanguínea invadiendo las mucosas de la región nasal y orofaríngea. Este proceso puede durar un largo período que puede extenderse hasta 20 años.

Esta enfermedad ha sido registrada en América desde el sureste de los EE.UU. hasta el norte de Argentina, con la excepción de Chile y Uruguay (Warren y Mahmoud 1984; Marzochi et al. 1999), del Noroeste Argentino (Valles Calchaquíes, Belén y Pampa Grande), así como en la Puna y de la zona sur del territorio de Bolivia (Mollinedo et al. 2004); es decir, se trata de una enfermedad tropical y subtropical. En su trabajo sobre leishmaniasis en poblaciones prehistóricas, Altamirano (2000) registró seis casos masculinos de edades entre 50 y 74 años, y un caso femenino de 35 años. Este autor sintetiza la problemática indicando que desde el período Formativo (3000-1000 AC) los movimientos de las tribus amazónicas en dirección a los Andes diseminaron no solamente la cerámica y plantas tropicales como la coca, el mate, la yuca, la ayahuasca, entre otros, sino que también las enfermedades. Los huaco-retratos de cerámica mochica atestiguan la antigüedad de la enfermedad en América del Sur (Allison 1984, 1993).

Las condiciones ambientales necesarias para la existencia de los flebótomos (calor y humedad) no existen en San Pedro de Atacama, por su ubicación en el salar de Atacama, el que forma parte del desierto de Atacama (ver Figura 1). Esta es una región extremadamente árida que se caracteriza por tener escasas precipitaciones y baja humedad ambiental, con grandes contrastes de temperaturas entre invierno y verano y entre el día y la noche; a ello 
se suma la altitud que sobrepasa los $2400 \mathrm{~m} . \mathrm{snm}$. Los pocos ríos son escuálidos y salinos y forman oasis en sus tramos finales. Este ambiente, con ligeras variaciones, ha sido el mismo desde hace miles de años; en consecuencia, no es probable que haya sido apto para el desarrollo de enfermedades tropicales como la leishmaniasis.

La zona endémica de leishmaniasis más cercana a San Pedro de Atacama corresponde a la llamada provincia de las Yungas en el norte de Argentina, integrante del Dominio Amazónico. Dicha provincia ecológica comprende una estrecha faja verde y angosta, ubicada sobre cordones montañosos, que se diferencia de la fría y árida Puna al oeste, y de la cálida y seca llanura chaqueña al este. Tiene un clima cálido y húmedo, con una estación seca en el invierno y en la primavera. Las nubes cubren estas selvas gran parte del año, proveyendo la humedad necesaria para la subsistencia de su exuberante vegetación y el mantenimiento del flujo de agua en los ríos y arroyos. Las Yungas se desarrollan entre los 400 y $3000 \mathrm{~m}$.snm, con diversidad de pisos vegetacionales, de acuerdo a la temperatura, la humedad y la precipitación; es así que se distingue el Bosque Montano (1500-3000 m.snm), la Selva Montana (700-1500 m.snm) y la Selva Pedemontana (400-700 m.snm). La Selva Montana que corresponde al sector de pre-Puna, es la franja altitudinal que acusa las máximas precipitaciones pluviales (más de $2000 \mathrm{~mm}$ anuales). Ocupa las laderas orientales de las primeras cadenas de montañas al noroeste (sierras de Santa Victoria, Zenta, Calilegua, Zapla, etc.) y constituye una selva muy densa, con un ambiente muy húmedo y sombrío. El ambiente descrito es óptimo para la existencia de los flebotomídeos vectores de la leishmaniasis, por lo que constituiría una de las zonas endémicas de esta enfermedad.

\section{* Contextualización bioantropológica}

Se analizó la diferenciación fenotípica entre las tres zonas de Coyo Oriental. La muestra estuvo constituida por 158 individuos y se trabajó con 35 variables craneométricas. El relevamiento métrico fue hecho de acuerdo con las normas de la Convención Internacional de Mónaco de 1906 (Wilder 1920; Comas 1966; Bass 1987). Esta muestra difiere de la más completa (255 individuos) empleada por Costa y colaboradores (2008), pues ahora fueron considerados solamente los individuos adultos de la colección (Cocilovo et al. 2011).

Mediante un proceso basado en el cálculo de componentes principales (PC) y la aplicación del modelo lineal general (GLM) se obtuvo un conjunto menor de variables libres de los efectos producidos por el dimorfismo sexual, la edad y la deformación artificial. Los datos originales fueron transformados por medio del análisis de componentes principales en un conjunto de 20 variables no correlacionadas, y luego se redujo la variación producida por el sexo, la edad y la deformación artificial empleando el Modelo Lineal General (GLM). Las diferencias fenotípicas entre las zonas Norte, Sur y Sur-Sur se evaluaron mediante técnicas de análisis estadístico multivariado.

La Zona Sur resultó significativamente diferente de las otras dos, pero no existen pruebas suficientes para establecer lo mismo con respecto a las zonas Norte y Sur-Sur, razón por la cual aquel grupo constituye el principal componente de la variabilidad total observada. Igualmente, los valores de distancias $\mathrm{D}^{2}$ indican que el grupo de la Zona Sur presenta las mayores distancias con respecto a los grupos de las zonas Norte y Sur-Sur, siendo menor la distancia entre estas dos últimas.

Los resultados están de acuerdo con el modelo de dispersión basado en las dos únicas variables discriminantes canónicas que explican la variación total. Por su parte, las distribuciones normalizadas de los individuos de cada sector por sus valores en la primera y en la segunda variable discriminante, muestran que el grupo de la Zona Sur se diferencia más de los otros dos por la primera variable canónica y que los grupos de las zonas Norte y Sur-Sur se diferencian entre sí por la segunda variable canónica. La variación observada en su mayor parte es provocada por la diferenciación morfométrica de la Zona Sur, la cual presenta las mayores distancias $\mathrm{D}^{2}$ de Mahalanobis con respecto a los otros dos grupos.

En este desarrollo, correspondiente a la historia de 20 generaciones, sorprende la variación fenotípica existente entre los individuos inhumados en cada sector sugiriendo, a la vez, la integración de tres componentes, asociados posiblemente con eventos de ocupación independientes. 
En síntesis, los resultados indican una manifiesta diferenciación de la Zona Sur respecto a los otros dos sectores (Norte y Sur-Sur) entre los cuales la semejanza es mayor. Esto es importante, ya que los cráneos en cuestión pertenecen a la Zona Sur del cementerio, la que no solo muestra una marcada variación fenotípica, sino que también, como se verá en el próximo acápite, alberga un relevante contexto de bienes foráneos.

\section{* Contextualización Cultural}

En las excavaciones de Le Paige, solamente los cráneos en buenas condiciones fueron recogidos e ingresados a la colección del Museo; el número de cráneos existentes es de 255. En sus contextos, además de alfarería, cestería, tejidos, gorros y otros artefactos, se registran 55 tabletas para inhalar alucinógenos, varias de ellas asociadas con Tiwanaku, así como numerosos cestos bordados con lanas de colores (tipas), relacionadas con el Noroeste Argentino (Llagostera 1995). Este sería el único cementerio que muestra lo que Le Paige (1972-73) denomina "martillos-maza" de piedra, a los que se supone asociados con la minería.

Los contextos de las tumbas de los individuos afectados con leishmaniasis no difieren mayormente del común de los enterratorios del cementerio de Coyo Oriente, conteniendo básicamente objetos domésticos como alfarería, cestería, calabazas, capachos, cucharas, bolsitas con comida y amuletos, no destacando ni desmereciendo en cantidad y calidad el promedio del resto de los ajuares del cementerio.

Coyo Oriente es un cementerio monocomponente, adscrito exclusivamente a la fase Coyo del período Medio. Ya hemos dicho que de acuerdo a las notas de Le Paige se le puede dividir en tres zonas: Norte, Sur y Sur-Sur. La secuencia cronológica para Coyo Oriente queda confirmada por las dataciones por termoluminiscencia obtenidas por nosotros: para la Zona Sur-Sur se tiene una fecha de 720 DC, para la Zona Sur dos fechas de 900 y 1080 DC, y para la Zona Norte dos dataciones de 1085 y 1230 DC. Los contextos y las fechas disponibles hablarían en favor de una secuencia que avanza en el tiempo de sur a norte.

En cuanto a la situación por sitios en relación a la presencia de tabletas y tubos en las tumbas que tienen ar- tefactos tiwanaku, se observa que en Coyo Oriente, de un total de 21 tumbas con tabletas y 24 con tubos, hay 11 con tabletas y 18 con tubos tiwanaku; hay cinco casos en que coinciden tabletas y tubos de la misma filiación; un caso con tableta y tejido. Todos los que tienen tubo tienen tableta; excepto dos casos de tableta sin tubo y cinco casos de tubos sin tabletas. De las 11 tabletas que hemos clasificado con iconografía tiwanaku para este sitio (Llagostera 2006a), siete provienen de la Zona Sur, tres de la Zona Sur-Sur y solo una de la Zona Norte. De los 18 tubos tiwanaku, 11 proceden de la Zona Sur, cinco de la Zona Sur-Sur y dos de la Norte.

Entre otros bienes de filiación tiwanaku, hay dos ejemplares de cerámica, uno viene de la Zona Sur y el otro no es posible asignarlo a ninguna. Por su parte, tres textiles provienen de la Zona Sur, tres de la Zona Sur-Sur y uno de la Norte. Otras tumbas albergaban conchas marinas trasandinas de Strophocheilus oblongus, nueve martillos y 11 casos de cestos tipo "tipas" del Noroeste Argentino (Llagostera 1995). A todo esto, se agregan siete hachas de las cuales cinco son simbólicas (hoja de hueso o de madera) y dos de metal, todas asociadas a tabletas tiwanaku, excepto una que solo tiene un tubo tiwanaku; en dos casos, se asocian tableta y tubo tiwanaku. Uno de los portadores de hachas tiene brazalete y cintillo de cobre; otro 13 colgantes de cuatro puntas del mismo metal. En una tumba se registra un adorno de plata acompañado de un tubo tiwanaku.

El flujo en la distribución de objetos tiwanaku por zonas en Coyo Oriente, relacionándolo con la proporción de éstos con el número total de individuos en cada una de ellas, resulta ser la siguiente: para la Zona Sur-Sur se registran 11 objetos, lo que da un 11.8\% (N=93); para la Zona Sur, 22 objetos con un $12.7 \%(\mathrm{~N}=172)$ y para la Zona Norte, cuatro objetos con 3.4\% ( $\mathrm{N}=116)$. Entonces, el flujo en las zonas Sur-Sur y Sur concentra la mayor proporción de bienes foráneos, en tanto que la Zona Norte muestra una notable disminución.

De acuerdo a lo expuesto, la Zona Sur posee contenidos contextuales más abundantes y representativos de procedencia foránea, en comparación con la Zona Norte, donde los ajuares y ofrendas son más sencillos, mientras que los de la Zona Sur-Sur, están en una posición intermedia. 


\section{* Deformación CRANEANA ARTificial}

De los cráneos de Coyo Oriente afectados con leishmaniasis, uno presenta deformación tabular erecta (3938), otro, circular oblicua (5377) mientras que los otros dos no han sido deformados (3984 y 4156 ).

Según Costa y colaboradores (2008), la mayoría de los habitantes de Coyo Oriente se deformaba la cabeza, con predominio del tipo tabular erecto. El tipo circular erecto está escasamente representado, siendo mucho más popular entre las mujeres. El circular oblicuo es aún menos frecuente, siempre con mayor ocurrencia en mujeres. En cuanto a la deformación tabular oblicua, se encontraron solamente tres casos en dos mujeres y en un hombre. Uno de los cráneos que nos ocupan (5377) presenta deformación circular oblicua, siendo uno de los 16 cráneos circulares presentes en Coyo Oriente; lamentablemente no cuenta con asignación de zona en el cementerio. Los otros tres cráneos provienen de la Zona Sur y uno de ellos tiene deformación tabular erecta, mientras que los otros no están deformados.

Para el área de Tiwanaku, si tomamos en conjunto los datos aportados por Posnansky (1914), Hjorjo y Lindh (1947) y Ruiz y colaboradores (1984), se daría la siguiente distribución: tabulares $12.4 \%$, circulares $67.3 \%$, ambos erectos y oblicuos, y 10\% no deformados. Esto apoyaría, en principio, la propuesta de Torres-Rouff (2007) para San Pedro de Atacama, donde la influencia de esa entidad altiplánica, en el período Medio, podría ser inferida por su asociación con la deformación circular, aunque los registros contextuales por tumba no indican la relación exclusiva con un determinado tipo deformatorio (Torres-Rouff 2002). En Coyo Oriente se observó, desde el sector más temprano al más tardío, una tendencia a la disminución de los tipos tabulares (61\%, 52\% y 46\%) y al incremento de los circulares ( $2 \%, 5 \%$ y $13 \%)$, mientras que los no deformados fluctúan en proporciones mayores a un tercio de las muestras (Costa et al. 2008).

\section{* Discusión y CONClusiones}

Un primer aspecto a considerar se relaciona con el registro de una enfermedad tropical en el desierto de Atacama, donde no existen condiciones ambientales compatibles para que ella se desarrolle. Se hace evidente que el contagio tuvo que darse fuera de este territorio y, según los antecedentes expuestos, debería haber ocurrido en las laderas orientales de los Andes, a una distancia no menor de $700 \mathrm{~km}$ de San Pedro de Atacama.

Aceptando el aloctonismo de esta patología en San Pedro de Atacama, la discusión se centra en la manera como las personas resultaron contaminadas por ella. De acuerdo a lo que hemos venido argumentando, se podrían admitir dos posibilidades: 1) habrían sido atacameñas que viajaron a la zona endémica y contagiado ahí; 2) habrían sido originarias de una zona endémica que vinieron a vivir, ya infectadas, a San Pedro.

En cualquier caso, queda en evidencia la interacción entre San Pedro de Atacama y las regiones trasandinas endémicas de leishmaniasis, a través de la movilidad humana. En este sentido, pensamos que la actividad caravánica es central, pues si las afectadas fueran atacameñas, ello significaría que la movilidad caravanera era tan extensa como para alcanzar hasta esas lejanas tierras donde pudieron contraer la enfermedad.

Según Llagostera (2006b), en San Pedro de Atacama se habría consolidado una red de flujo interétnico con la Puna y la Circumpuna, por intermedio de la cual se logró concretar el ideal andino de complementariedad y reciprocidad, en un hábitat de muy baja densidad demográfica y de grandes extensiones desérticas. Esta red estaría articulada por nodos de ensamble cuyas jefaturas habrían manejado el flujo de bienes, amparadas en un complejo trasfondo sociopolítico.

En consecuencia, las relaciones interétnicas habrían tenido su escenario en puntos nodales ubicados en localidades intermedias, hacia donde convergían e interactuaban los diversos grupos del entorno (Llagostera 1996). De esta forma, los bienes serían objeto de sucesivos intercambios, trasladados entre diferentes territorios, de manera que las caravanas del salar de Atacama no necesariamente estarían obligadas a alcanzar tierras bajas orientales para obtener, por ejemplo, las preciadas semillas de cebil o las hojas de coca, tan importantes para sus ritos religiosos, sino que las obtendrían en uno de esos nodos donde las intercambiarían por bienes producidos en los oasis del Salar. 
En el caso que los atacameños realmente hubieran llegado físicamente hasta las tierras endémicas, sería lógico esperar una mayor ocurrencia de casos de leshmaniasis en San Pedro de Atacama; sin embargo, su mínima frecuencia arguye en favor de que no era habitual para ellos realizar estos viajes de larga distancia, reforzando la propuesta de los nodos intermedios como la práctica común.

Otra cuestión de peso tiene que ver con el sexo de las personas afectadas. Con la cautela necesaria que debemos tener en las comparaciones de situaciones etnográficas con las arqueológicas, nos guía la fuerte impresión de que, en su composición, las caravanas del pasado no debieron ser extremadamente diferentes a las que hasta pocas décadas atrás ocurrían en los Andes, cuando eran constituidas exclusivamente por hombres (Flores Ochoa 1977). Por lo mismo, se hace notoria la ausencia de individuos masculinos enfermos de leishmaniasis.

Nos encontramos frente a un filtro de género cuya respuesta habría que buscarla en causales biológicas o culturales. Desde el punto de vista biológico se podría pensar en un tipo de inmunidad de los varones frente a la enfermedad; no obstante, por los antecedentes epidemiológicos actuales se sabe que hombres y mujeres son igualmente afectados, hecho confirmado por los casos masculinos encontrados en Perú (Altamirano 2000).

Con posterioridad al trabajo en que Costa y colaboradores (2009) dan cuenta de la determinación de leishmaniasis en San Pedro de Atacama, Marsteller y colaboradores (2011) retomaron el tema de esa enfermedad en los oasis, extendiéndose en un cráneo con la misma patología procedente de Tchecar, el que también resultó ser femenino. Sugieren como una de las causas de la diferenciación sexual, la posibilidad de que los varones infectados pudieran haber muerto antes de que la infección se hiciera crónica. Consideramos que ello tendría que estar reflejado en las tasas de mortalidad, las que entonces deberían mostrar un desequilibrio entre los sexos, con desventaja para los hombres; pero esto no es lo que sucede en esta población. Admiten también la posibilidad de que haya ocurrido un factor cultural en relación a una diferenciación en los niveles de cuidado de los enfermos según el sexo que favorecería a uno de ellos; en este caso, las mujeres. Estudios anteriores demuestran que los habitantes de los oasis atacameños constituían una sociedad altamente homogénea en cuanto a la salud, dieta, uso del cuerpo, entre otros, así que dicha aseveración no se justificaría (Costa y Neves 1990). Otra sugerencia alternativa es una división sexual de tareas durante los viajes a tierras bajas, de tal manera que las mujeres incursionarían a lugares con mayor exposición a los insectos vectores, no así los varones. Pensamos que esta propuesta tiene poco asidero tanto por las razones ya expuestas como por el hecho de que, en una amplia zona endémica de leishmaniasis sería difícil que miembros de una caravana se dispersaran de tal manera que algunos quedaran expuestos a los vectores y otros no. En consecuencia, la respuesta a esta diferenciación sexual debemos buscarla en factores culturales relacionados con las normativas de interacciones matrimoniales.

La posibilidad de establecer nexos de parentesco político (matrimoniales) entre los habitantes de los oasis de San Pedro y personas foráneas cobra vital importancia como mecanismo de sustento de la propia red complementaria, tanto a nivel de enlace con territorios y productores lejanos, como para dar soporte al sistema de prestigio. Existen evidencias en la arqueología local de la presencia de forasteros residiendo en los oasis, situación que no nos cabe duda, hizo parte del contexto general de la red complementaria que se comprometía a través de lazos de parentesco.

La presencia de gente foránea enterrada en los cementerios de los oasis san pedrinos nos habla de personas que no estuvieron de paso, sino que se establecieron en esta localidad. No se trata de población flotante ni de colonos, sino de personas que se integraron plenamente a compartir la vida cotidiana, por lo menos la última parte de su vida; gente que vino para quedarse y falleció en estos oasis. Este fenómeno podría considerarse en la categoría de coloniaje; sin embargo, la distribución de estos extranjeros en los cementerios sigue el mismo patrón que los objetos foráneos en las tumbas, es decir, es mixto, aleatorio y minoritario. Este patrón nos permite descartar el sistema de colonias, ya que, si así fuera, se deberían encontrar cementerios o sectores de cementerios destinados solamente a estos grupos; en consecuencia, se trata de personas que se integraron plenamente a la vida cotidiana local, probablemente a través de nexos matrimoniales. 
Todos los individuos afectados de Coyo Oriente proceden de la Zona Sur. Tal como ya se señaló, el análisis de diferenciación fenotípica entre las tres zonas del cementerio arrojó una significativa diferencia entre la Zona Sur y aquellas Sur-Sur y Norte. Igualmente, los valores de distancias $\mathrm{D}^{2}$ indican que el grupo de la Zona Sur presenta las mayores distancias con respecto a los otros dos grupos. En consecuencia, habría que aceptar que en dicha zona existe un componente bioantropológico introducido, el cual sería el causante de la diferencia detectada. Hipotéticamente, ello debería corresponder a la presencia de fenotipos foráneos. Este planteamiento, a su vez, tendría coherencia con el hecho que la Zona Sur también posee objetos más abundantes y representativos de procedencia foránea, tanto del Noroeste Argentino como de filiación tiwanaku. Este panorama refuerza las probabilidades de que las personas con leishmaniasis sean alóctonas a la genealogía local.

Por otro lado, Costa y colaboradores (1995) cuantificaron la microdiferenciación craneométrica existente entre grupos locales en función del tiempo, espacio y contextos culturales, tratando de establecer el grado de proximidad biológica entre éstos, al tiempo de detectar posibles aportes genéticos foráneos. Fueron estudiados 233 individuos de Larache, Catarpe 1, Quitor 6, Solcor 3 y Coyo 3, resultando que las mujeres de este último presentaron las mayores distancias en relación a las mujeres de los demás sitios, distancias que son estadísticamente significativas. Esto respalda al ayllu de Coyo como un lugar abierto a la recepción de un activo flujo no solo de bienes foráneos, sino también de personas, dando al género femenino un importante protagonismo.

Parece probable que los nodos del sistema reticular planteado por Llagostera (1996), fueran los lugares de encuentro y la ocasión para la búsqueda de consortes y la celebración de pactos matrimoniales, sin necesidad de que los atacameños se desplazaran a lugares remotos con este fin. Sin embargo, sería esperable que, a través de estas alianzas matrimoniales, también varones de otras tierras pudieran haber llegado al Salar y que algunos de ellos estuviesen también infectados con leishmaniasis, lo cual, como se ha señalado, no sucedió. La ausencia de casos masculinos sugeriría la posibilidad de que el sistema de dichas alianzas haya sido patrilocal, en el cual las mujeres pasaban a vivir en las comunidades de sus maridos.
Frente a este paradigma, el "filtro de género" al que nos referimos anteriormente, respondería a una causal cultural y no biológica.

De los cráneos afectados de Coyo Oriente, dos presentan deformación craneana: uno, tabular erecta y el otro, circular oblicua. Dado que las deformaciones craneanas son consideradas como indicadores de identidad étnica (Dembo e Imbelloni 1938; Gerszten 1993), éste es un rasgo interesante de discutir, especialmente en lo que respecta a la deformación circular la que, como ya se ha señalado, son vistas como propias de poblaciones altiplánicas. En los oasis del salar de Atacama, los tipos deformatorios mayoritarios son los tabulares, en tanto que los circulares son más escasos, situación a la que no escapa Coyo Oriente. El cráneo afectado con deformación circular es uno de los 16 de esta categoría presentes en este cementerio. Se suma a lo anterior el hecho de que los individuos con deformación circular son mayoritariamente femeninos, y que una de las dos acompañantes de la afectada en la tumba también presenta deformación circular.

La baja presencia de la deformación circular en San Pedro de Atacama nos lleva a aceptarla como un rasgo foráneo, delatando a sus portadores como originarios de otras etnias. En consecuencia, la asociación de leishmaniasis con deformación circular, en este caso, no resulta casual sino que refuerza la foraneidad de los individuos afectados con esta patología. Lamentablemente no se tiene información sobre deformación craneana para las tierras endémicas de la enfermedad debido a que las propias características ambientales que la favorecen han impedido que se conserven los restos humanos; pero es posible que su vecindad con el altiplano aumente las probabilidades de que se haya practicado la deformación circular.

Aunque los contextos funerarios asociados a las tumbas de estas mujeres no muestran objetos que puntualmente se puedan relacionar a territorios trasandinos, el cementerio Coyo Oriente es el sitio en San Pedro de Atacama que presenta la mayor cantidad de artefactos de dicho origen (Llagostera 1995). En este sitio hay 11 tumbas que contienen "tipas" o cestos bordados, los que se reconocen como asociados a la Cultura Aguada del Noroeste Argentino, por su iconografía relacionada con el personaje con propulsor y proyectiles, comúnmente representado en la alfarería grabada de dicha entidad. Otro elemento 
que liga a Coyo Oriente con el Noroeste Argentino es la presencia de una figura femenina tallada en madera, cuyos atributos estilísticos permiten también asimilarla a Aguada. Estos elementos aportan antecedentes que refuerzan la idea de nexos con la región oriental de los Andes y que, junto con el flujo de objetos, habrían permitido el traslado de gente hacia este lado de la cordillera. Coyo Oriente es el sitio que registra la mayor cantidad de tabletas tiwanaku en San Pedro de Atacama (12); le siguen Quitor 6, Solcor 3 y Quitor 5 (7, 7 y 6 respectivamente); por último, Sequitor Alambrado Oriente (3) y Quitor 2 (1). Coyo Oriente contiene la mayor variedad de representaciones y al interior del sitio las tabletas de esta filiación representan el 15.7\% (Llagostera 2006a).

Por último, no podemos dejar de mencionar los análisis de isótopos de estroncio realizados en estos cráneos, cuyas tazas han entregado similitud entre ellos y los encontrados en otras muestras de San Pedro de Atacama, por lo cual se ha postulado un origen local para las mujeres enfermas (Marsteller et al. 2011). No obstante, consideramos que los argumentos aquí presentados aportan mayor soporte a la hipótesis de foraneidad de los individuos analizados. Sería necesario poder establecer las firmas de isótopos de estroncio en las zonas endémicas de leishmaniasis para descartar la eventualidad de que dichas signaturas fueran similares a las del salar de Atacama.

Como se ha dicho, las características desfigurantes de las lesiones pueden aparecer con bastante posterioridad a la infección primaria, por lo que el individuo bien puede desarrollar parte de su vida adulta con cierta normalidad. No obstante, cabría suponer que la apariencia de un enfermo de este tipo fuera causa de una segregación social, tal como se constata que ocurre con enfermos modernos de leishmaniasis (WHO 2007), por lo que sería espera- ble que los ritos mortuorios para estas personas reflejaran dicha discriminación. De ser así, ello se evidenciaría en la ocurrencia de tumbas individuales ubicadas en sectores separados del cementerio; no obstante, y a juzgar por las características de sus enterramientos, estas mujeres de Coyo Oriente aparecen plenamente integradas a su grupo, enterradas en el cementerio de la comunidad $y$, en tres de los casos, compartiendo lo que podrían ser tumbas familiares. Se puede pues suponer que en una sociedad de rasgos igualitarios como habría sido la san pedrina, una persona adoptada como miembro del grupo desde larga data, no fuera objeto de discriminación y rechazo, sino que seguiría manteniendo su lugar dentro del grupo.

Como conclusión, postulamos que las mujeres de Coyo Oriente afectadas con leishmaniasis fueron originarias de regiones endémicas al oriente de los Andes. Es posible suponer que el cambio de residencia se debiera a matrimonios exogámicos patrilocales, matrimonios que probablemente se celebraban a una edad temprana de la mujer, cuando aún no se habría manifestado visiblemente la enfermedad. En consecuencia, cuando esas manifestaciones se hicieron presentes, varios años después, las mujeres ya se encontrarían plenamente integradas a la comunidad de sus cónyuges.

Según lo expuesto, se plantea que las caravanas de Atacama viajaban hasta los puntos nodales donde, además de las transacciones de trueque de bienes y de la celebración de ceremonias y protocolos de consolidación de nexos interétnicos, se llevaban a cabo pactos matrimoniales, de tal manera, que al regresar a los oasis, los varones traían mujeres procedentes de lejanas tierras orientales, sin que permeara la necesidad de que ellos hubieran llegado hasta allá.

\section{$\diamond$ Referencias citadas}

ALLISON, M., 1984. Paleopathology in Peruvian and Chilean populations. En Paleopathology at the origins of agriculture, M. Cohen y G. Armelagos (Eds.), pp. 515-529. Academic Press, Orlando.

1993. VIII.79. Leishmaniasis. En The Cambridge world History of human disease, K. Kiple (Ed.), p. 832. Cambridge University Press, Cambridge.
ALTAMIRANO, A., 2000. Comprometiendo la estructura osteo-facial de las poblaciones humanas del antiguo Perú por la leishmaniasis tegumentaria de forma mucosa. Tesis Doctoral. Fundação Oswaldo Cruz, Escola Nacional de Saúde Pública, Río de Janeiro. http://portalteses.cict.fiocruz.br/transf. php?script $=$ thes_cover\&id $=000108 \& \operatorname{lng}=p t \& n r m=i s o$. Acce so en abril de 2005 . 
BASS, W., 1987. Human osteology: A laboratory and field manual of the human skeleton. Missouri Archaeological Society, Columbia.

BUIKSTRA, J. y D. UBELAKER, 1994. Standards for data collection from human skeletal remains. Arkansas Archeological Survey Research Series 44, Fayetteville.

COCILOVO, J., H. VARELA y A. LLAGOSTERA, 2011. Armando el rompecabezas de San Pedro de Atacama: El sitio Coyo Oriental y la cuestión de los sectores del Padre Le Paige desde la antropología biológica. Revista de Antropología 23 (1): 149-172.

COMAS, J., 1966. Manual de antropología física. Universidad Autónoma de México, Instituto de Investigaciones Históricas, Sección de Antropología, México D.F.

COSTA, M. A. y W. NEVES, 1990. Osteobiography and late agriculture social organization at San Pedro de Atacama, Chile.American Journal of Physical Anthropology 81: 208-209.

COSTA, M. A., A. LLAGOSTERA, F. ROTHHAMMER y C. SILVA, 1995. Microdiferenciación craneométrica entre las poblaciones agroalfareras de San Pedro de Atacama, Chile. Hombre y Desierto: Una perspectiva cultural 9: 27-31.

COSTA, M. A., A. LlagOsterA y J. COCILOVO. 2008. La deformación craneana en la población prehistórica de Coyo Oriente, San Pedro de Atacama. Estudios Atacameños, Arqueología yAntropología Surandinas 36: 29-42.

COSTA, M. A., C. MATHESON, L. LACHETTA, A. LlAGOSTERA y O. APPENZELLER, 2009. Ancient leishmaniasis in a highland desert of northern Chile. PLoS One 4 (9): e6983. Epub.

DEMBO, A. y J. IMBELLONI, 1938. Deformaciones intencionales del cuerpo humano de carácter étnico. Humanior Secc. A, 3, Buenos Aires.

GERSZTEN, P., 1993. An investigation into the practice of cranial deformation among the pre-columbian peoples of northern Chile. International Journal of Osteoarchaeology 3 (2): 87-98.

FLORES OCHOA, J., 1977. Los pastores de Paratía. Una introducción a su estudio. Instituto de Estudios Peruanos (IEP), Lima.

HJORJO, C. y J. LINDT, 1947. Anthropological investigation of the craneal and skeletal material from Dr. Stig Ryden's archaeological expeditions to the bolivian highlands. En Archaeological Research in the Higlands of Bolivia, S. Ryden (Ed.), Appendix II: 517-559. Göteborg.

LE PAIGE, G., 1972-73. Tres cementerios indígenas en San Pedro de Atacama y Toconao. Actas del VI Congreso Nacional de Arqueología Chilena. Boletín de Prehistoria número especial, pp. 163-187.
LLAGOSTERA, A., 1995. El componente Aguada en San Pedro de Atacama. Boletín del Museo Chileno de Arte Precolombino 6: 9-34.

1996. San Pedro de Atacama: Nodo de complementariedad reticular. En La integración surandina cinco siglos después, X. Albó, M. Arratia, J. Hidalgo, L. Núñez, A. Llagostera, M. Remy y B. Revesz (Eds.), Universidad Católica del Norte y Centro de Estudios Regionales Andinos Bartolomé de Las Casas, pp. 17-42. Estudios y Debates Regionales Andinos 91, Cuzco.

2006a. Contextualización e iconografía de las tabletas psicotrópicas tiwanaku de San Pedro de Atacama. Chungara, Revista de Antropología Chilena 38 (1): 83-111.

2006b. San Pedro de Atacama y el sistema reticular de interacción puneña. En Esferas de Interacción prehistóricas y fronteras nacionales modernas: Los Andes Sur Centrales, H. Lechtman (Ed.), pp. 303-322. Instituto de Estudios Peruanos (IEP) e Institute of Andean Research (IAR), Lima.

MARSTELLER, S., C. TORRES-ROUFF y K. KNUDSON, 2011. Pre-Columbian Andean sickness ideology and the social experience of leishmaniasis: A contextualized analysis of bioarchaeological and paleopathological data from San Pedro de Atacama, Chile. International Journal of Paleopathology 1 (1): 24-34

MARZOCHI, M. y K. MARZOCHI, 1994. Tegumentary and visceral leishmaniasis in Brazil-emerging anthropozoonosis and possibilites for their control. Cad. Saúde Pública 10 (2):359-375.

MARZOCHI, M., A. SCHUBACH y K. MARZOCHI, 1999. Leishmaniose tegumentar americana. En Parasitologia humana e seus fundamentos gerais, B. Cimerman y S. Cimerman (Eds.), pp. 39-64. Editora Atheneu, São Paulo.

MOLLINEDO, S., M. TORREZ, E. HOLGUÍN y F. VARGAS, 2004. Leishmaniasis en Bolivia: Epidemiología de fin de siglo. Revista Médica 7. http://www.galenored.com/trabajos/archivos/129.pdf. Acceso 13 marzo 2007.

OAKLAND, A., 1992. Textiles and ethnicity: Tiwanaku in San Pedro de Atacama, north Chile. Latin America Antiquity 3 (4): 316-340.

ORTNER, D. y W. PUTSCHAR, 1981. Identification of pathological condition in human skeleton remains. Smithsonian Institution Press, Washington D.C.

POSNANSKY, A., 1914. Una metrópoli prehistórica en la América del Sud, 1, D. Reiner (Ed.). Ernst Vohsen, Berlín.

RUIZ, A., M. MARRODAN y M. PUIG-SAMPER, 1984. Cráneos normales y deformados de Tiahuanaco. Estudios de Antropología Biológica. II Coloquio de Antropología Física Juan Comas, pp. 449-474. México D.F. 
TARRAGÓ, M., 1989. Contribución al conocimiento arqueológico de las poblaciones de los oasis de San Pedro de Atacama en relación con los otros pueblos puneños, en especial, el sector septentrional del Valle Calchaquí. Tesis Doctoral, Facultad de Humanidades y Artes, Universidad Nacional de Rosario, Rosario.

TORRES-ROUFF, C., 2002. Cranial vault modification and ethnicity in Middle Horizon, San Pedro de Atacama, applications of environmental stress. Current Anthropology 43 (1): 163-171

2007. La deformación craneana en San Pedro de Atacama. Estudios Atacameños, Arqueología y Antropología Surandinas 33: 25-38.
WARREN, K. y A. MAHMOUD, 1984. Tropical and geographical medicine. McGraw Hill, Nueva York.

WILDER, H., 1920. A laboratory manual of anthropometry. P. Blakiston's Son \& Co., Filadelfia.

WORLD HEALTH ORGANIZATION, 2007. The disease and its epidemiology. http://www.who.int/leishmaniasis/disease_epidemiology/en/index.html. Acceso 15 enero 2007.

2007. Essential leishmaniasis maps. WHO/CSR/EDCUNAIDS Map production: Public Health Mapping Group Communicable Diseases (CDS) World Health Organization. http:// www.who.int/leishmaniasis/leishmaniasis_maps/en/index. html. Acceso 13 marzo 2007. 